The extent to which Islamic banking transactions are compatible with the rules of Islamic economics

\title{
Badr, OM
}

http://hdl.handle.net/10026.1/10727

\subsection{7/Islec.30-3.6}

Journal of King Abdulaziz University, Islamic Economics

King Abdulaziz University

All content in PEARL is protected by copyright law. Author manuscripts are made available in accordance with publisher policies. Please cite only the published version using the details provided on the item record or document. In the absence of an open licence (e.g. Creative Commons), permissions for further reuse of content should be sought from the publisher or author. 
مجلة جامعة الملك عبدالعنيز: الاقتصاد الإسلامي، م30 ع3، ص ص: 167-184 (محرم 1439/ أكتوبر 2017) DOI: 10.4197 / Islec. 30-3.6

\section{مدى توافق معاملات البنوك الإسلامية مع قواعد الاقتصياد الإسلامي}

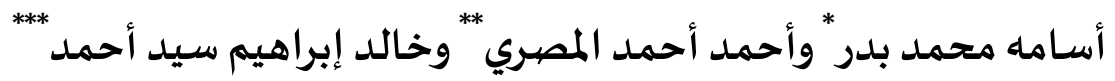

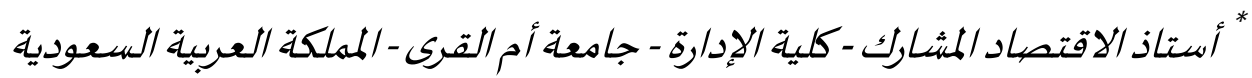

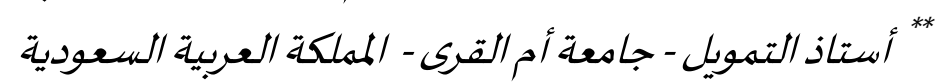

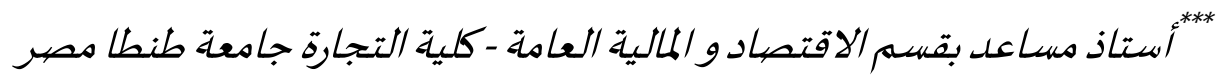

المستخلص. تشير أدبيات التمويل الإسلامي إلى أن أول تطبيق لفكرة مصارف إسلامية تمت في الريف

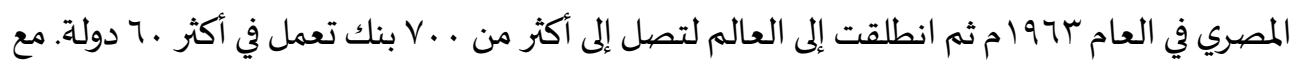

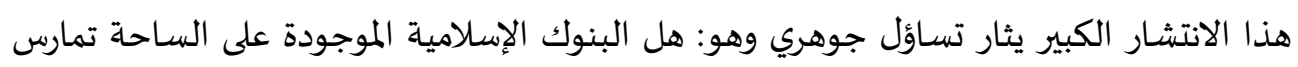

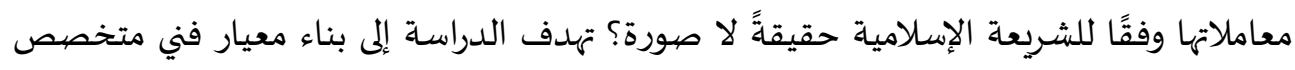
لتقييم ومعرفة مدى التزام البنوك الإسلامية بقواعد الاقتصاد الإسلامي أثناء قيامها بالعمليات المصرفية. ومن ثم تم تصميم معيار فني تم تطبيقه على عينة من البنوك الإسلامية في الوطن العربي.

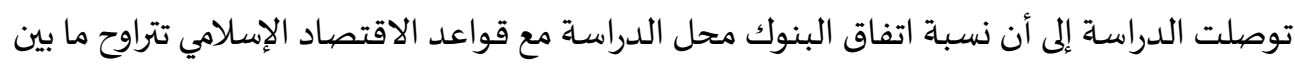

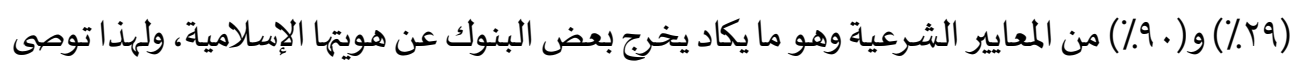

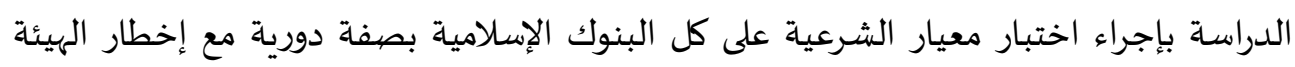

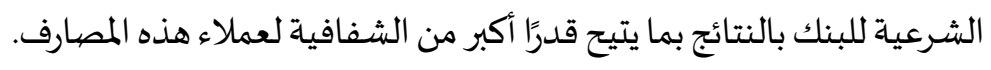
الكلمات الدَّالة: الاقتصاد الإسلامي، البنوك الإسلامية، المعايير المصرفية الشرعية، المعاملات المصرفية الإسلامية، تقويم أداء البنوك الإسلامية.

تصنيف E4 : JEL

تصنيف B04, Q23, I0, L11, L21 : KAUJIE 


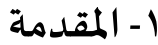

مهما كان نوعها وحجمها، بشرط أن لا يؤدي هذا التملك

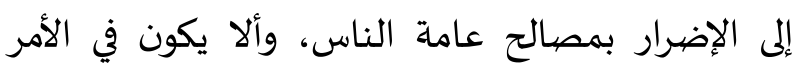

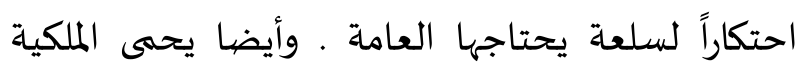

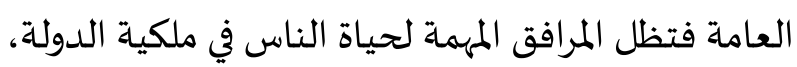

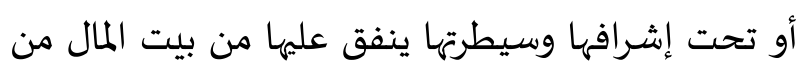

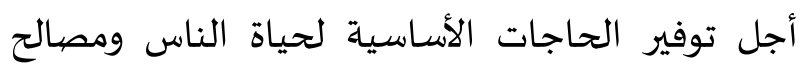
المجتمع.

وهو اقتصاد يدعم الشفافية فقد حض الإسلام على الشفافية من خلال نصوص كثيرة منع الرسول صلى الله عليه وسلم التجار من تلقي القوافل القادمة من البادية. كما يحمي حقوق العاملين فيحض على أن يعطى الأجير أجرة قبل أن يجف عرقة، ويهتم بالمسؤولية الاجتماعية والإنسانية من خلال فرض الزكاة على المكلفين وعلى المانى القادرين لتغطية احتياجات الفقراء وغير القادين الإين بالإضافة إلى المشاركة التطوعية من خلال الصدقات الصات الفات والأوقاف لتغطية حاجات الفقراء بما يؤدى إلى تحقيق التكافل الاجتماعي، بالإضافة إلى أنه اقتصاد يدعم التهاء لأنمية التادية

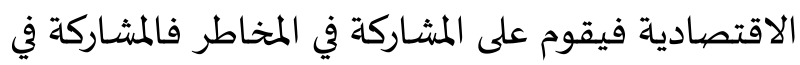
الريح والخسارة، هي قاعدة توزيع الثروة بين رأس المال والعمل، وهي الأساس الذي يحقق العدالة في التوزيع. وآثار المبدأ الثاني من مبادئ الاقتصاد الإسلامي في تحريم الربا بنوعيه ربا الفضل وربا النسيئة وهو من الأمور القطعية المحرمة نصيًا في القرآن كما في سورة البقرة

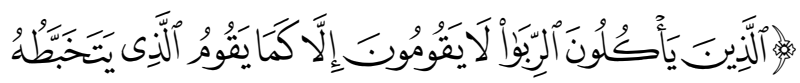

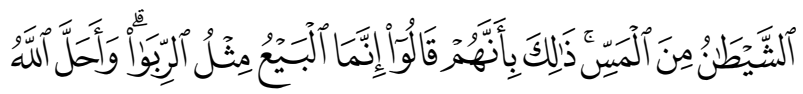

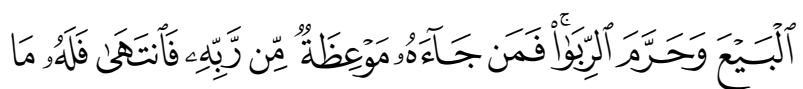

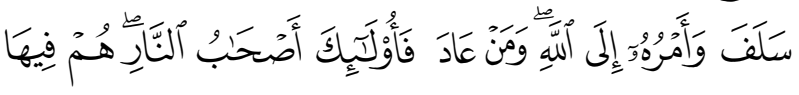

يقوم الاقتصاد الإسلامي على مبدأين أساسيين أولهما أن المال مال الله ونحن مستخلفون فيه: وبذلك فنحن

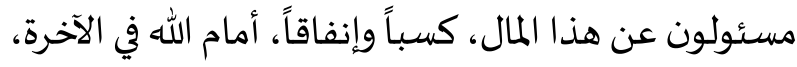

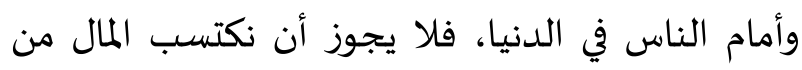
معصية، أو ننفقه في حرام، ولا فيما يضر الناس. أما المبدأ الثاني فهو أن دور المال - في شكله النقدي - هو أداة لقياس القيمة، ووسيلة للتبادل التجاري، وليس سلعة من السلع، فلا يجوز بيعه وشراؤه، ولا تأجيره.

ويعكس الاقتصاد الإسلامي قواعد ومفاهيم الدَّين

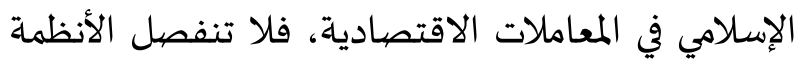

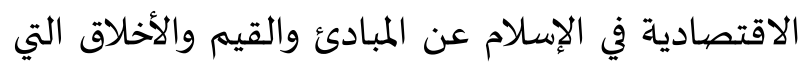
جاء بها الإسلام، حيث يوازن بين المصلحة الفردية الإناية

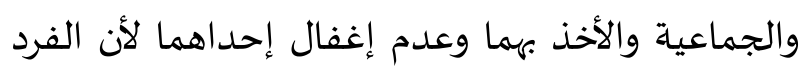
والجماعة ليسا خصمين، وعند تعذر التوفيق بينهما تُغَلَّب الجنب مصلحة الجماعة، كنهي النبي عن تلقي الركبان، وبيع الحاضر للبادي، والاحتكار، والشفعة. كما أن الإسلام

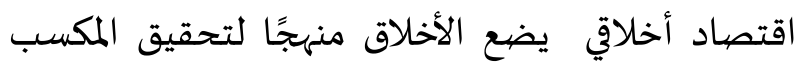

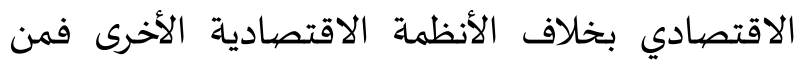
أخلاق التاجر المسلم السماحة، الصيدق، الأمانة،

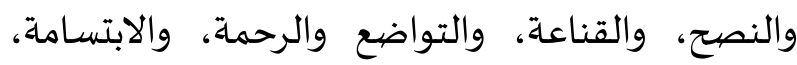

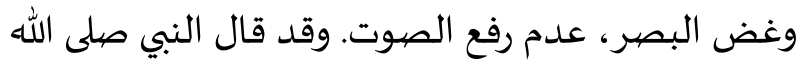
عليه وسلم "التاجر الصدوق الأمين المسلم مع الشهداء

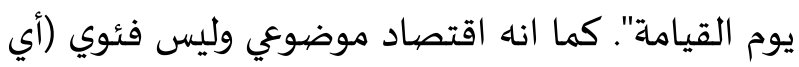

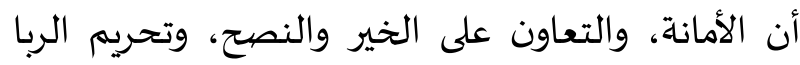
مطبقة على الجميع (مسلمين وغير مسلمين). كما يهتم نظام الاقتصاد الإسلامي بالمحافظة على المافي

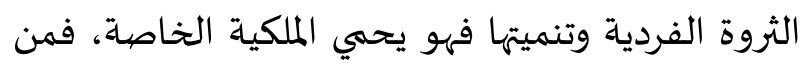
حق الأفراد تملك الأرض والعقار ووسائل الإنتاج المختلفة 
لظروف ليس هنا مجال الخوض فيها ولكن بالرغم من عدم اكتمالها، إلا أهها عكست رغبة المسلمين في إيجاد بدائل

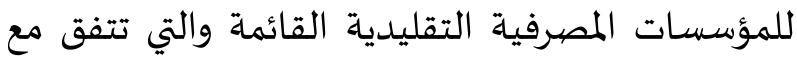
الشريعة الإسلامية والعمل في إطار نظام اقتصادي

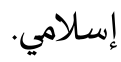

وقد شهدت السبعينيات من القرن الماضي انطلاقة جديدة لفكرة إنشاء المصارف والمؤسسات المالية الإسلامية. ففي عام الوإم أسس أول مصرف في مصر المراء

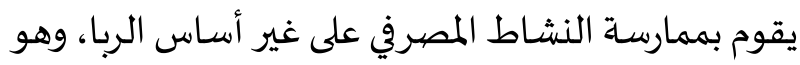

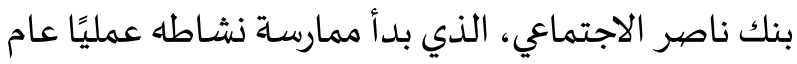

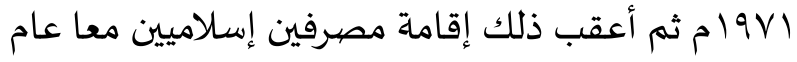
ا 19 م هما بنك دبي الإسلامي والبنك الإسلامي للتنمية في جدة ثم توالت حركة تأسيس البنوك الإسلامية بظهور مصرف فيصل الإسلامي عام 19VVام، وبيت التمويل الكويتي، أعقها البنك الإسلامي الأردني في عام 9 ام ثم الأمي

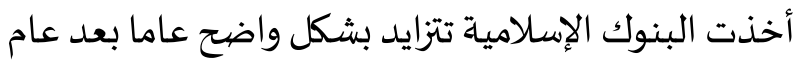

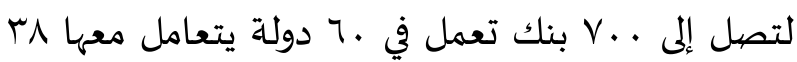
مليون عميل حول العالم، فمن المتوقع أن يزيد معدل

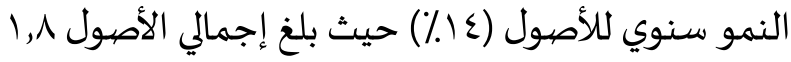

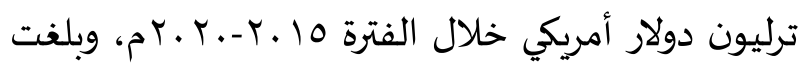

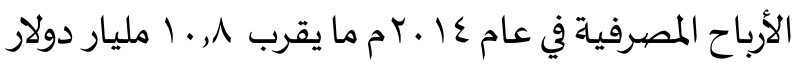

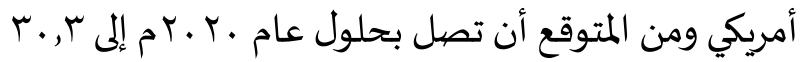

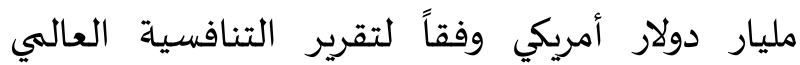

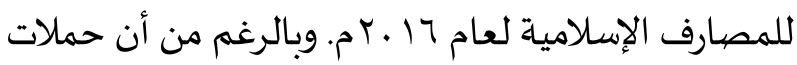
التشويه المتعمد لفكرة البنوك الإسلامية مازالت مستمرة

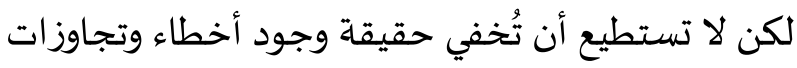

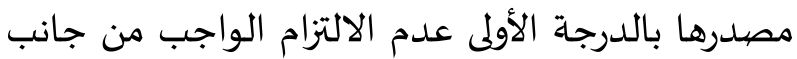
تلك البنوك والعاملين فهها بالأسس والمعايير الشرعية.

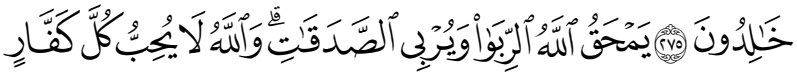

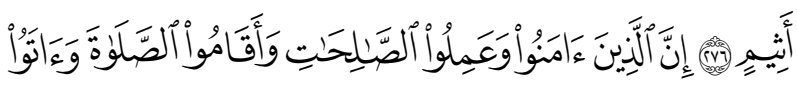

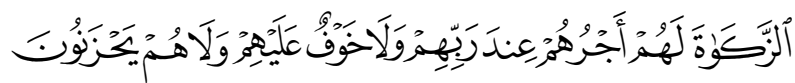

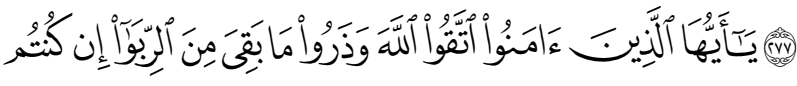

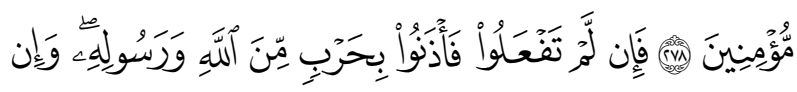

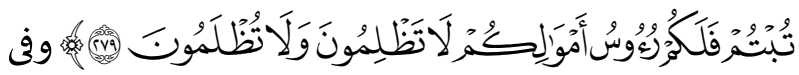

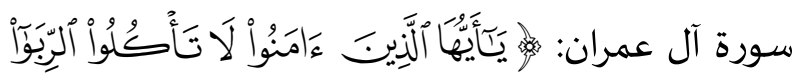

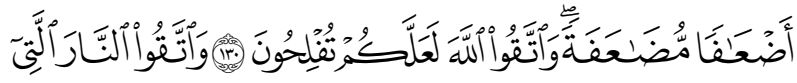

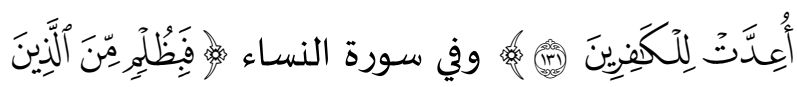

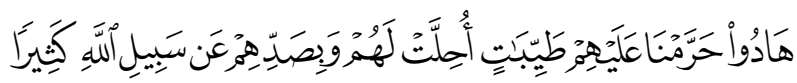

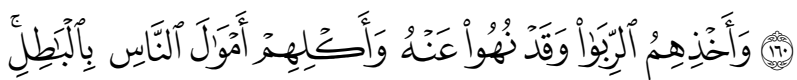

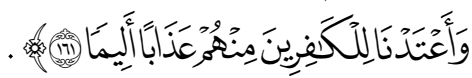
وكنتيجة لهذا التحريم الصريح والقاطع للربا ولتحري الحلال في المعاملات الاقتصادية بدأت تتبلور فكرة البنوك الإسلامية في محاولة للوصل إلى بنوك غير ربوية، بنوك بلا فوائد، وظهرت إلى حيز الوجود في الريف المصري في العام

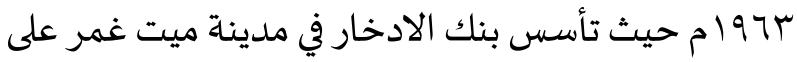
يد الدكتور أحمد عبد العزيز النجار كأول بنك لا يعتمد على وجود فوائد وإنما يكون عملية شراكة بين المودعين والمستثمرين والبنك ويتم تقسيم العائد الفعلي لهذه الشراكة بين الأطراف الثلاثة، وتعد هذه أول تجربة - في حدود ما لدينا من مصادر - في العصر الحديث في مجال العمل المصرفي الإسلامي، ونتيجة لعدم تعاملها بالفائدة حظيت هذه البنوك المحلية بتشجيع المواطنين ودعمهم

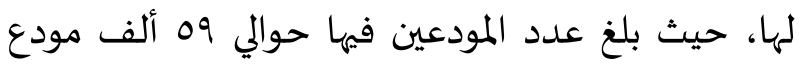

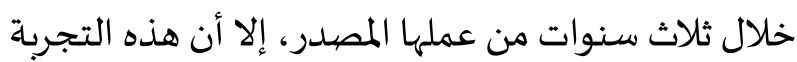

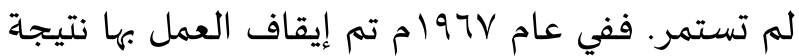


(أ) الطابع العقائدي

البنوك الإسلامية جزء من النظام الاقتصادي الإسلامي ولهذا تخضع للمبادئ والقيم الإسلامية والتي تقوم على أسـاس أن المال مال الله سبحانه وتعالى وأن الإنسان مستخلف فياه وسيحاسب عليه في الآخرة كما قال

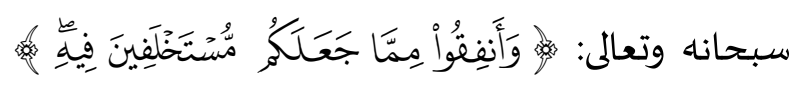

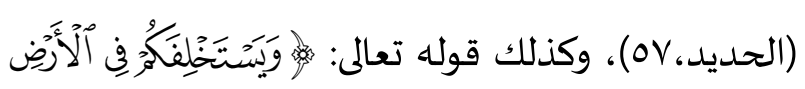

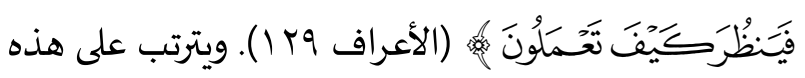
الخاصية أن تتحرى البنوك الإسلامية التوجيهات الدينية

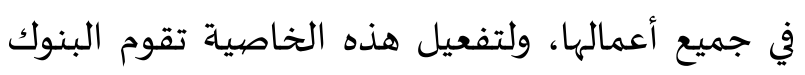

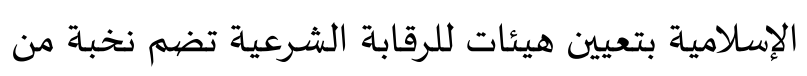
علماء الفقه والاقتصاد الإسلامي وتعرض عليها جميع

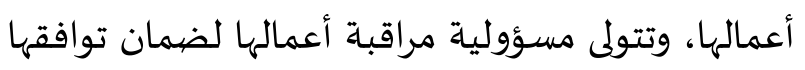

$$
\text { مع الشريعة الإسلامية. }
$$

(ب) عدم التعامل بالفائدة

الأساس الذي قامت عليه البنوك الإسلامية هو تطهير العمل المصرفي من إثم الربا، التزاما بقوله تعالى:

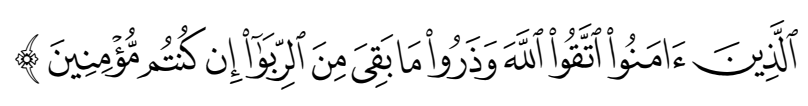

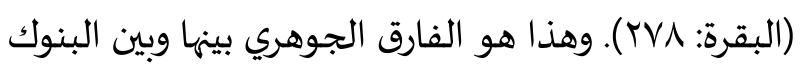

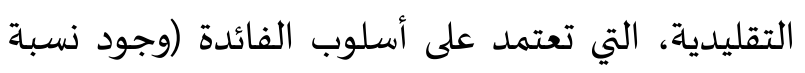

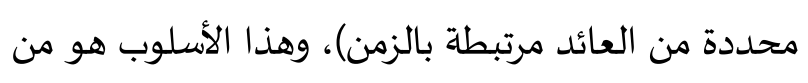
الربا الذي حرمتا الشريعة الإسلامية تحريما قاطعا.

\section{(ج) إرساء مبدأ المشـاركة في الربح والخسارة} و يعد ذلك تطبيقا للقاعدة الفقهية "الغنم بالغرم، والغرم بالغنم"، وهي تعني أن التكاليف والخسائر التي

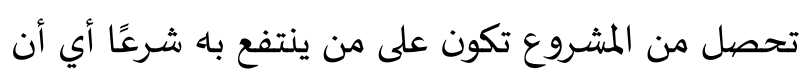

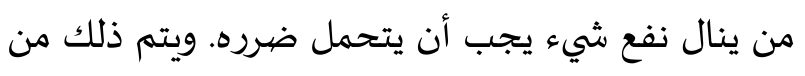

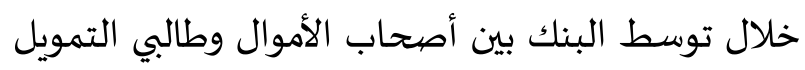

\section{r - يين البنك التقليدي ونظيره الإسلاهي}

فبينما البنك التقليدي هو مؤسسـة مالية، وظيفتها الرئيسة تجميع الأموال من أصحابها في شكل ودائع جارية

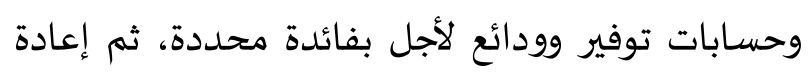
إقراضها لمن يطلبها بفائدة أكبر، ويربح البنك الفرق بين

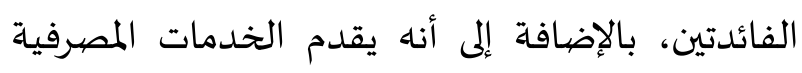

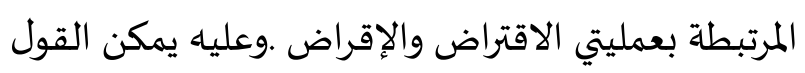
بأن البنك هو وسيط مالي أو بصيغة أخرى مقترض يتاجر

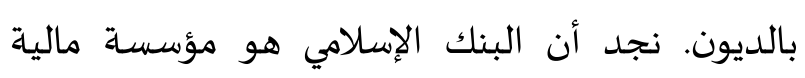

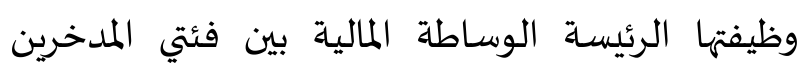
والمستثمرين وأداء الخدمات المصرفية المنضبطة في إطار

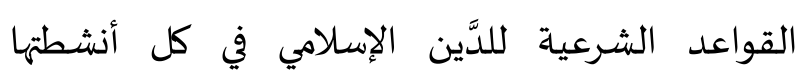
الاستثمارية والخدمية فتكون كالوعاء يمتزج فيه فكر استثماري اقتصادي سليم ومال يبحث عن ربح حلال، لتخرج منه قنوات تجسد الأسس الجوهرية للاقتصاد الإسلامي، من أجل المساهمة في دفع عجلة التنمية الاقتصادية والاجتماعية في البيئة التي تعمل فيها (النجار (191).

وبالتالي فإن مهمة البنك الإسلامي والتي تنبثق من رؤية الإسلام لمسؤولية الإنسان في عمارة الكون وعن التوجيهات الواردة في الكتاب والسنة في مجال المال والمعاملات لا لإنال تجعله يقف عند الامتناع عن الربا بل تقف بالضرورة وبأمر الشارع في قلب العملية الإنتاجية بل إن قربها وبعدها

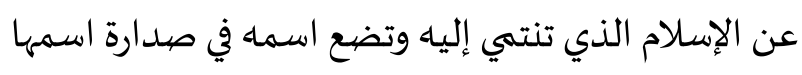

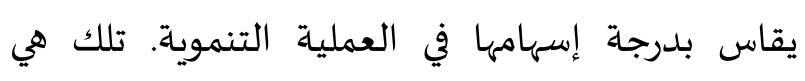
أساسيات مؤسسة البنك الإسلامي الذي تطرحاء كتجسيد للمبادئ والأركان التي جاء بها الفكر الإسلامي في المجال الاقتصادي وبالتالي فإن من أهم الخصيائص المميزة للبنوك

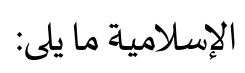


r- الحاجة إلى تطوير معاييرخاصة بالمصهارف الإسلامية لاحظ المهتمون بمسيرة البنوك الإسلامية أن

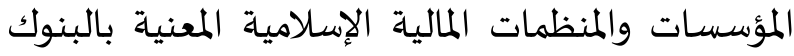

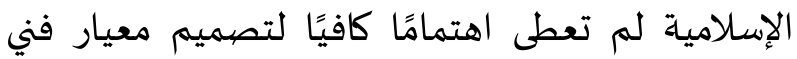
متخصص للبنوك الإسلامية وتركت الجهات التقليدية تقوم بذلك باستخدام مؤشرات تقليدية لا تعبر عن الطبيعة الذاتية للبنك الإسلامي حيث تستخدم نفس

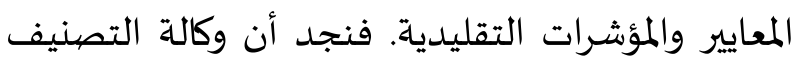

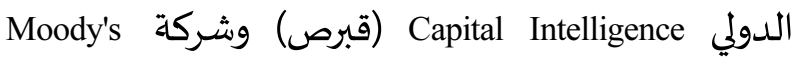
(لندن) تستخدمان معايير لتصنيف وقياس أداء البنوك الإسلامية لا تتناسب مع طبيعة عملها أو الغرض الذى الذى الدياء أنشئت من أجله. ويثار تساؤل ما هي حاجتنا إلى معيار خاص بالبنوك الإسلامية. حيث أن طبيعة النشاط بالبنوك الإسلامية تختلف اختلافا جوهرياً عن طبيعة

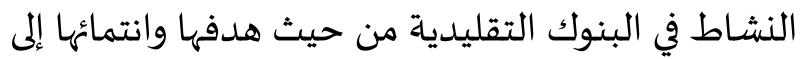
تطبيق قواعد الاقتصاد الإسلامي ولذلك فإن استخدام معايير التقييم التقليدية بشكل عام لكل من البنوك الاقدي

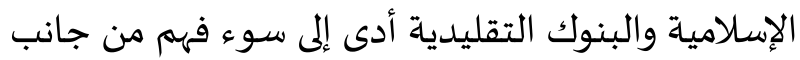
السلطات الرقابية لأداء البنوك الإسلامية، الأمر الذي الذياء

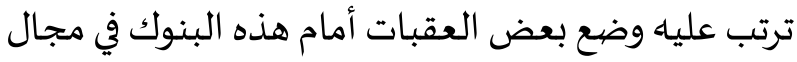
التوسع والانتشار. كما أن استخدام معايير تقييم أداء البنوك التقليدية في تقييم البنوك الإسلامية أدى إلى: عدم إظهار مدى التزام البنوك الإسلامية بقواعد

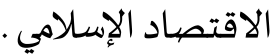
عدم إظهار مدى قيام البنوك الإسلامية بأنشطتها الاجتماعية وذلك لعدم وجود معايير خاصة لقياس الأداء الاجتماعي للبنوك الإسلامية ودية
مع عدم قطع المخاطرة وإلقائها على طرف دون آخر وتستعيض البنوك الإسلامية عن أسلوب الفائدة بأسلوب المشاركة والذي يقوم على توزيع مخاطر العمليات

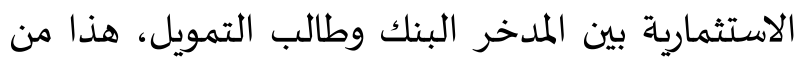
حيث التنظير أما الممارسة فهي شيء آخر. (د) إحداث تنمية اقتصادية واجتماعية حقيقية في المجتمع

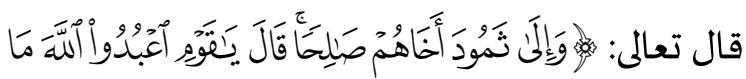

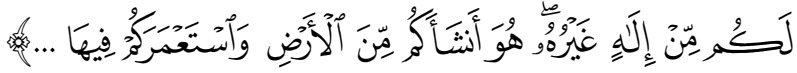
(هود:ا7)، فخضوع البنوك الإسلامية للمبادئ والقيم الإسلامية، يؤدى إلى زبادة دورها الاجتماعي من خلال

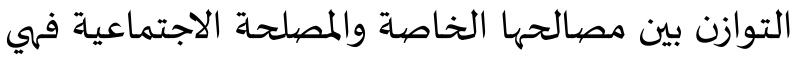
تراعي المصالح الاجتماعية ولو أدى ذلك إلى التضحية ببعض مصالحها الخاصة. (ه) إرساء مبدأ التكافل الاجتماعي

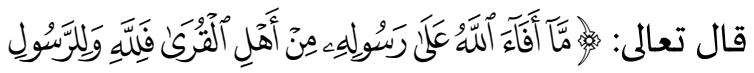

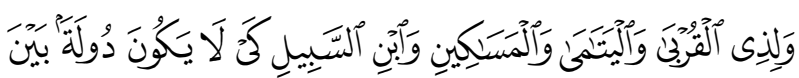

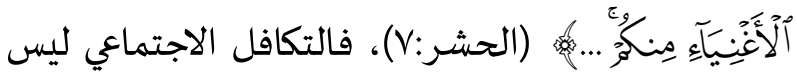
فقط بجمع الزكاة وصرفها في مصارفها الشرعية، وإنما أيضا بالسعي إلى تحقيق عدالة في توزيع عوائد الأموال المستثمرة وتعظيم العائد الاجتماعي للاستثمار. ومع تزايد أعداد البنوك الإسلامية وكثرة إقبال المودعين

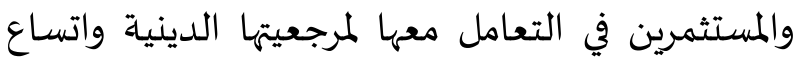
حجم أنشطها على مستوى العالم واستقطابها لشريحة كبيرة من المتعاملين وضعت كثير من البنوك لفظ "الإسلامي" بجوار اسمها ولكنها لا تراعي السلوك الشرعي في تعاملاتها، فكيف نعرف البنك الإسلامي حقيقة من غيره؟ 
دراسة الساعاتي (V. . . م) شرعية وأساليب البنوك في التمويل الإستهلاكي ولم تتطرق إلى مدى التزام البنك

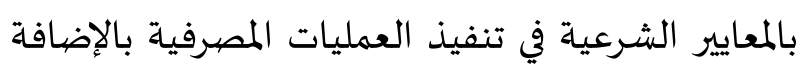

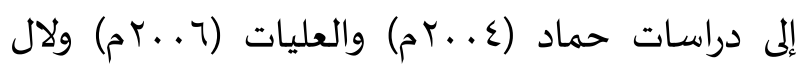

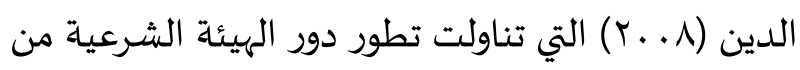
الدور الإستشاري إلى الدور الرقابي من حيث أهميتها،

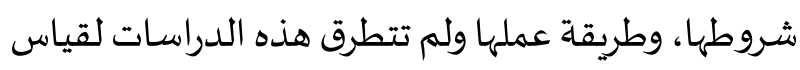
مدى التزام البنك الإسلامي بقواعد الاقتصاد الإسلامي في

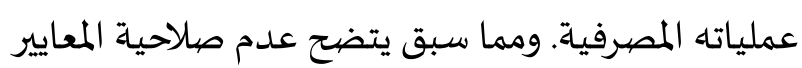

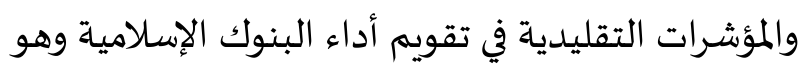

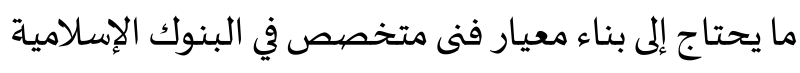
لتقييم ومعرفة مدي التزامها بقواعد الاقتصاد الإسلامي

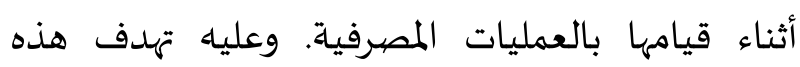
الدراسة إلى تطوير معيار فنى لقياس مدى توافق معاملات

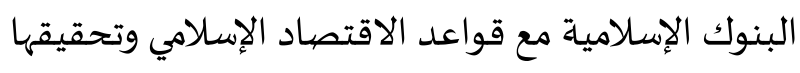

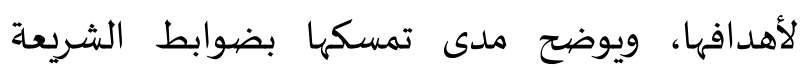

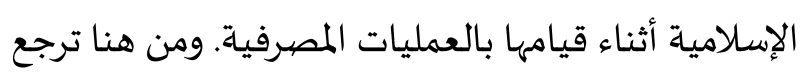
أهمية هذا الدراسة حيث أنه ههدف إلى إيجاد معيار يوضح الميح

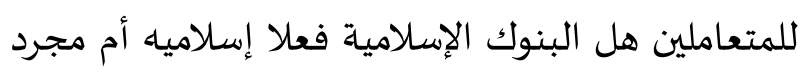

$$
\text { اسم يساعدها في اجتذاب العملاء. }
$$

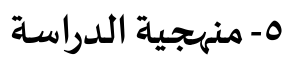

(1) تصيميم المعيار الفني

حتى يمكن وضع معيار فنى لتقييم شرعية أداء البنوك

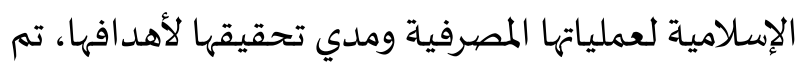
تصميم منهجية منبثقة من منهجية دلفى وهى تقنية

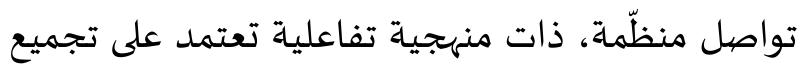

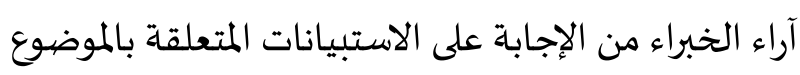

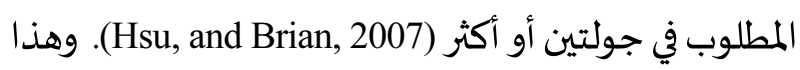
يضمن الابتعاد عن الآثار السلبية للمناقشات وجها لوجها
عدم وضوح أهداف البنوك الإسلامية ورسالها

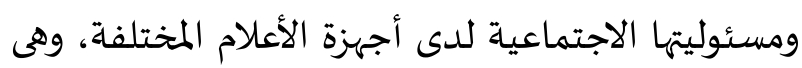

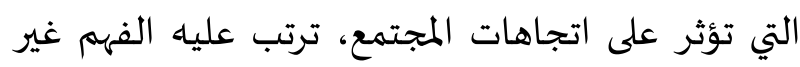
السليم للمجتمع بطبيعة وأهداف البنوك الإسلامية. ع- الدراسات السابقة

حاولت العديد من الدراسات تقييم وقياس فاعلية وكفاءة أداء البنوك الإسلامية مثل دراسات هدريش الراسي تقيث Hadriche (2015)

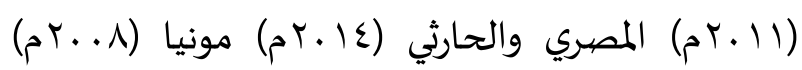

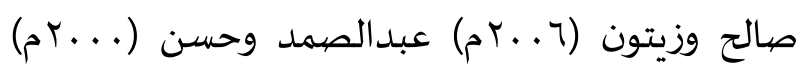

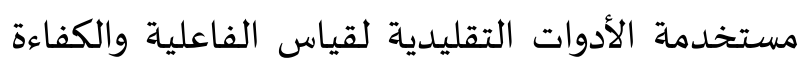
مثل اختبار DEA CAMEL والعديد من النسب المالية التي تقيس أداء البنوك وتصنفهم وتقارن بينهم متناسية اختلاف طبيعة البنوك الإسلامية عن البنوك التقليدية

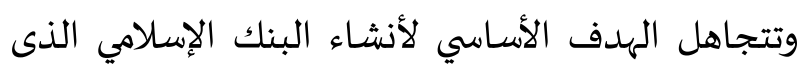

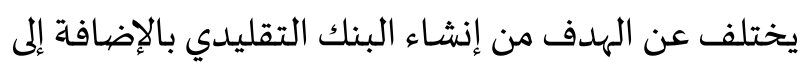

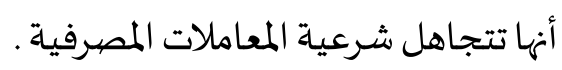
وفي نفس الوقت حاول الكثير من الاقتصاديين المهتمين

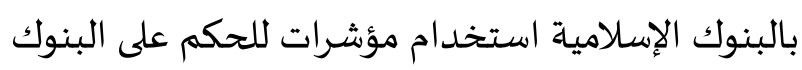

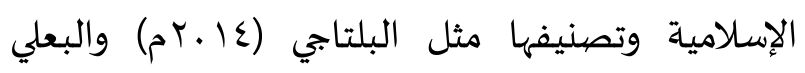

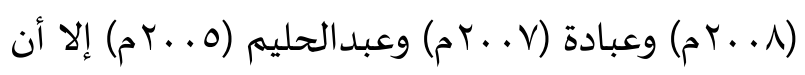

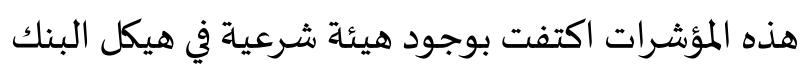

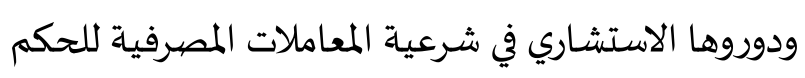

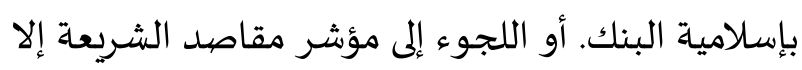

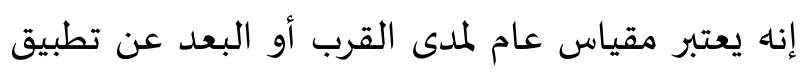

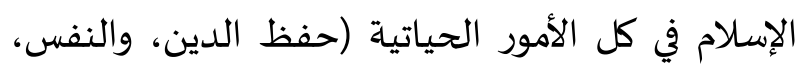

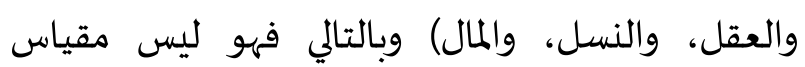

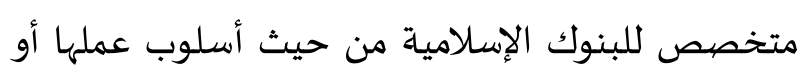

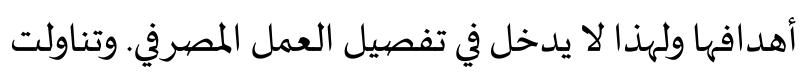


المنطلق قام فريق البحث باستنباط r I ا نقطة من هذه

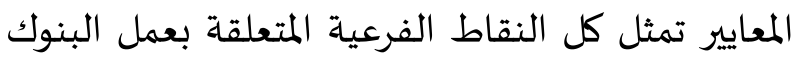
الإسلامية في المعايير الشرعية ومن ثم صياغة استبيان

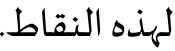

الخطوة الثالثة وتم فهيا عرض الاستبيان على فريق الخبراء والمتخصصين المشتغلين في البنوك الإسلامية في دول مختلفة (مصر وسوريا والأمارات وتونس) منفردين

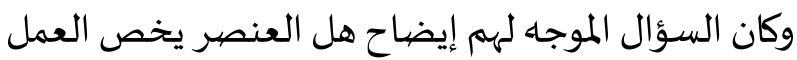
المصرفي أم لا وهل هو مفعل أم لا ـوكانت نتيجة الاستبيان

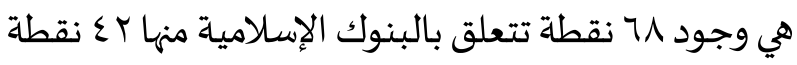
متداوله في العمليات المصرفية وجا نقطة غير متداوله في العمليات المصرفية وعه نقطة متعلقة بالمؤسسات الاقتصادية التي تنتهج من الاقتصاد الإسلامي أسلوب لعملها.

الخطوة الرابعة وتم فهها صياغة الجمل الشرعية التي تتعلق بالبنوك الإسلامية المستمدة من نتيجة الاستبيان السابق إلى أسئلة مباشرة تم وضعها في استبيان جديد. الخطوة الخامسة وتم فهها أخذ رأي مجموعة أخرى من الخبراء والمتخصصيين المشتغلين في البنوك الإسلامية في صياغة الأسئلة بحيث لا تقود إلى إجابه بعينها وسؤالههم عن درجة أهمية السؤال هل هو حاكم أم فرعى. وكانت

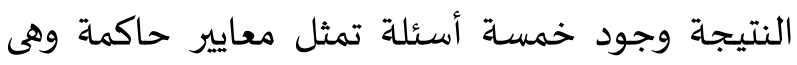
الشروط التي يجب توافرها في أي بنك يطلق على نفسة بنك إسلامي وتتمثل في وجود هيئة شرعية مؤهلة ذات سلطة، وعدم تحديد نسبة عائد ثابت مسبق على ودائع

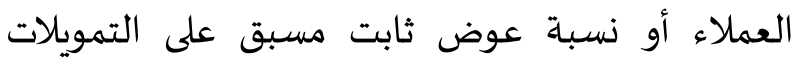

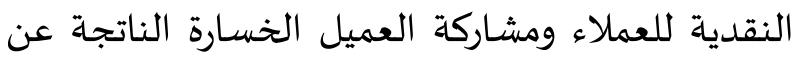

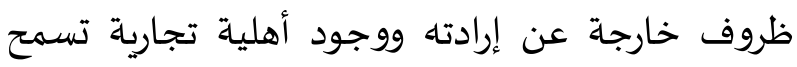
بشراء السلع وتخزينها والإتجار فيها، وبالتالي فإن عدم توفر تجارئ
ويحل المشاكل المعتادة في تفاعلات المجموعات بعد كل جولة بحيث يقوم الخبراء بمراجعة إجاباتهم على ضوء الردود من الخبراء الآخرين. ثم يتم تصفية أي محتوى غير الريا

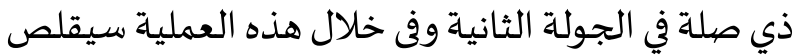
نطاق الإجابات وتتقارب آراء مجموعة الخبراء نحو الإجابة

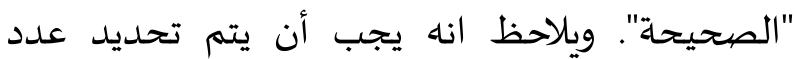

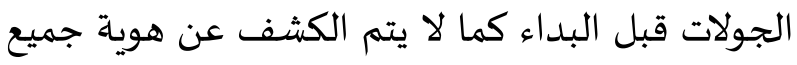
المشاركين حتى بعد الانتهاء من التقرير النهائي. ومن اهم

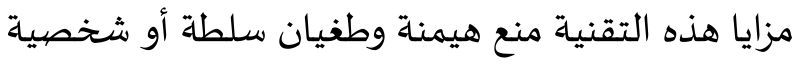
أو سمعة بعض المشاركين على الآخرين. بالإضافة إلى أهها

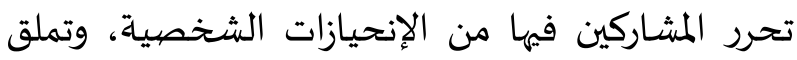

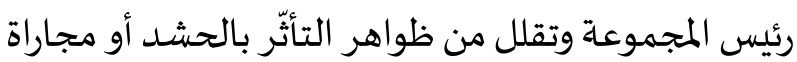
الفريق، وتسمح بحرية التعبير عن الرأي، وتشجع على النى

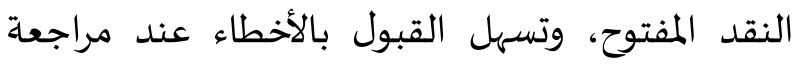

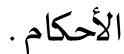
ولهذا فقد مر فريق البحث بخمس خطوات لتصميم

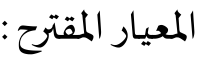

الخطوة الأولى وتم فهها التعرف على المعايير الشرعية التي يمكن استخدامها في التقويم والتي تتناسب مع طبيعة التئية تلك البنوك. وقد قام فريق البحث بتبنى المعايير الشرعية التي أصدرتها هيئة المحاسبة والمراجعة للمؤسسات المالية

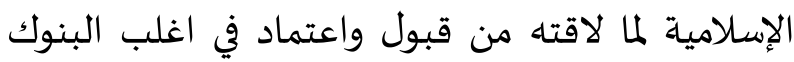

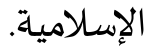

الخطوة الثانية وتم فهيا دراسة المعايير الشرعية التي تم تبنها وهى تتكون من ^^ معيار توضح الرأي الشرعي في أغلب المعاملات المالية التي يتم تداولها في الاقتصاد. وتحتوى على المعايير التي تتعلق بعمل البنوك الإسلامية والأخرى التي تتعلق بعمل المؤسسات الاقتصادية التي لتائي

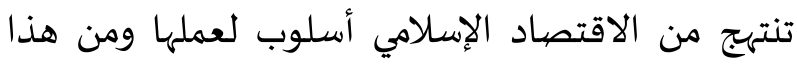


وعند التطبيق العملي استنادًا على المعلومات المستقاة من الإستبيانات وجدنا أن هناك بنكان فقط يلتزمان بشكل كامل بالمعايير الحاكمة وبالتالي يمكن أن يخضيعواليال للمرحلة الثانية وهي درجة الالتزام بالمعايير الفرعية. وقد اضطر الباحثون لدمج المعايير الحاكمة مع المعايير الفرعية في معيار واحد رغم إقرارهم بالاختلاف التام بين كلا النوعيين من المعايير، وذلك لعدم انطباق المعايير الحاكمة إلا على نسبة ضئيلة من عينة البحث وهو ما قد المد ودئ يدفع إلى اتهام نسبة كبيرة من هذه البنوك بعدم تحري الشريعة في معاملاتها ومن ثم قد يثبط محاولات الإصلاح

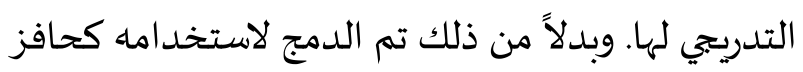
للبنوك ذات الدرجة المرتفعة على مزيد من الالتزام، لمديد و" كجرس" إنذار للبنوك ذات الدرجة المنخفضية لإعادة النظر كليًا في سياساتها.

في ضوء ذلك تم تعديل أسلوب إعداد المعيار الفني بحيث يعبر عن نسبة التزام البنك بقواعد الاقتصياد

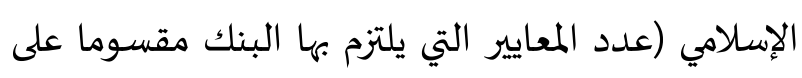

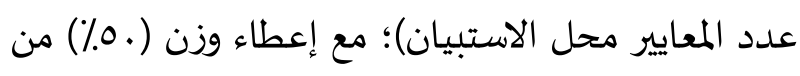

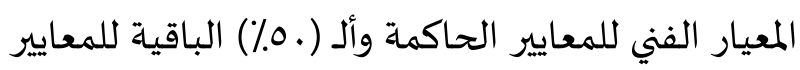
الفرعية. ويتكون هذا المعيار الفني من نسبة تتراوح ما بين الصفر (لا يتبع قواعد الاقتصاد الإسلامي) والواحد منديد الصحيح (تتفق مع قواعد الاقتصاد الإسلامي) سواء حاكماه أو فرعياء. وبتحليل إجابات الإستبيانات وجدنا فواعل أن الن

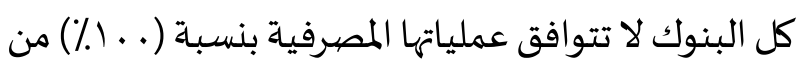
المعايير الشرعية. والجدول رقم (1) يلخص نتائج تحليل الاستبيان لكل بنك على حده من حيث المعايير الحاكمة والمعايير الفرعية وقيمة المعيار الفني المقترح.
أي من المعايير الحاكمة ينفى هوية البنك الإسلامية.

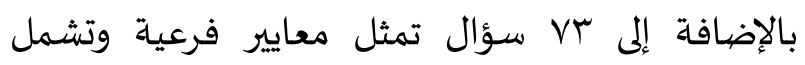

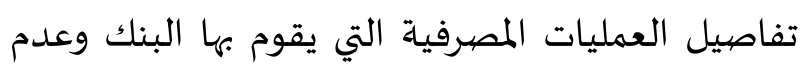
توفر أحد هذه المعايير يعتبر خطاً شرعيًا يؤثر في انتماء

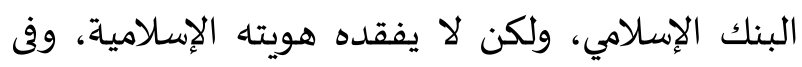

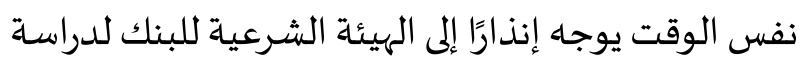

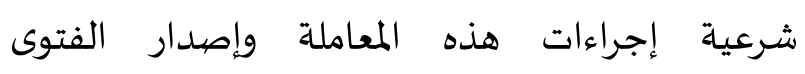
التصحيحية اللازمة بشأهها. (Y) تطبيق المعيار الفني بناءً على ما توافر لدينا من معطيات تم حصر البنوك

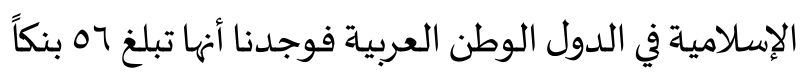

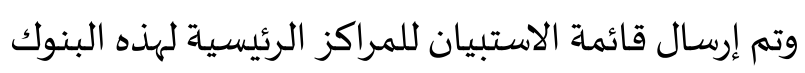

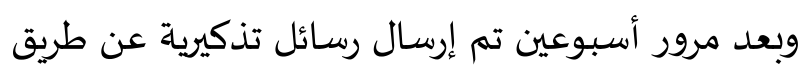

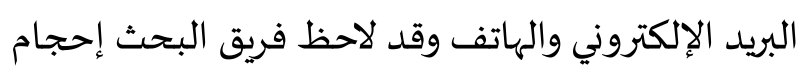

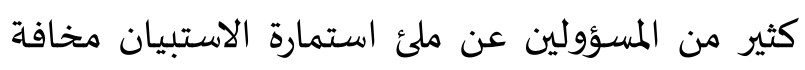
سقوط الهوية الإسلامية عن البنك، وكذلك رفضئ ملئ استماره المتلبان مخان

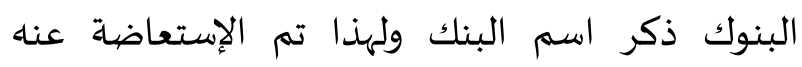

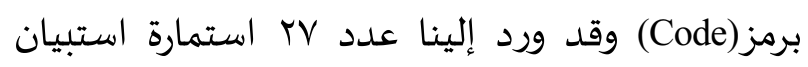

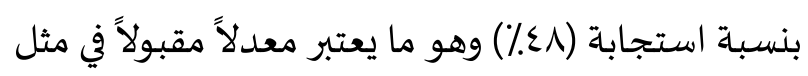

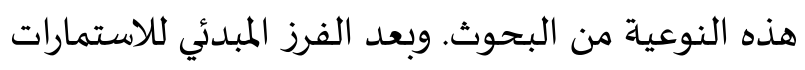
الواردة تم استبعاد ثلاثة استمارات لعدم اكتمالها ومن ثم ولمديه

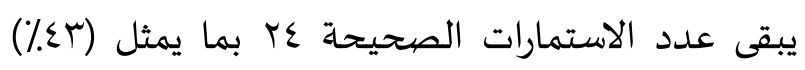
ورغم انخفاض هذه النسبة إلا أهها تعتبر مقبولة نظرًا للظروف والاضطرابات السياسية في بعض دول المنطقة.

$$
\text { 7- نتائج الدراسـة }
$$

تم تحليل بيانات الإستبيان الموزع على البنوك وفقًا

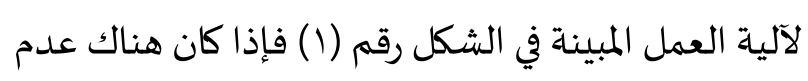
تطبيق لأحد المعايير الحاكمة فهذا مؤشر للتشكيك في

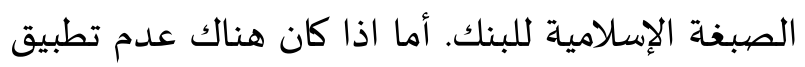
لأحد المعايير الفرعية فيفقد البنك درجه هذا المعيار. 
شكل رقم (1) آلية عمل وخريطة تدفق المعيار الفني

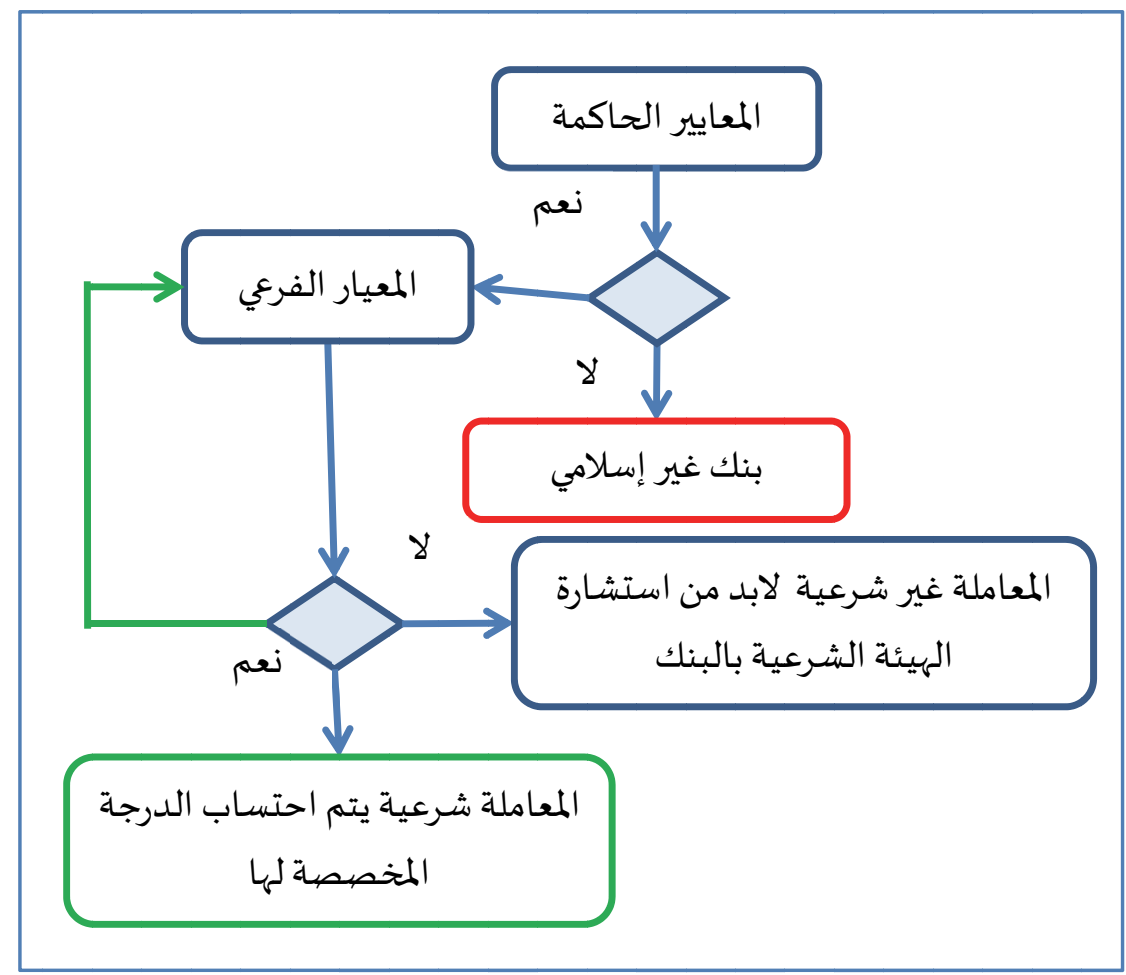

المصيدر: من إعداد الباحثين.

وقد اختلفت درجة توافق البنوك محل الدراسة على لم يمنحها البنك المركزي الأهلية التي تؤهلها للمتاجرة في

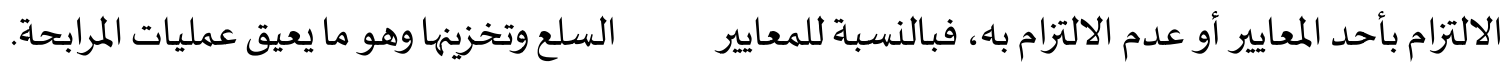
أما بالنسبة للمعايير الفرعية: انقسمت المعايير الفرعية

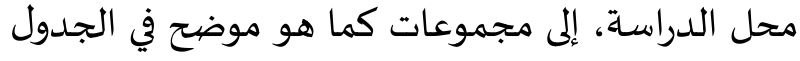

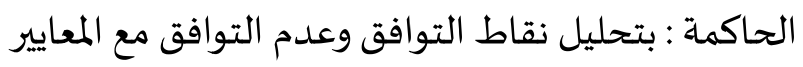

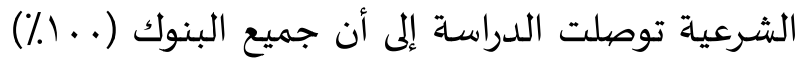

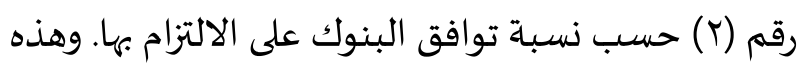
المجموعات تتدرج من "توافق ضعيف" وهي توضح المعايير

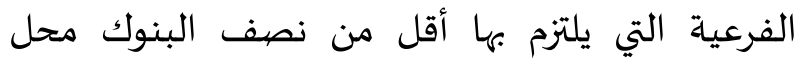

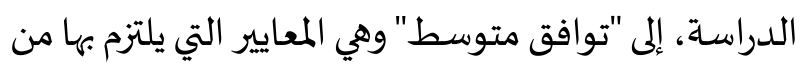

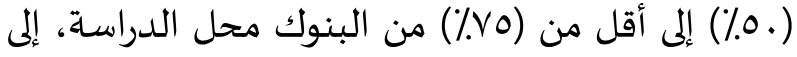

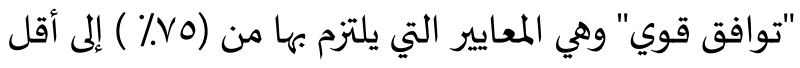

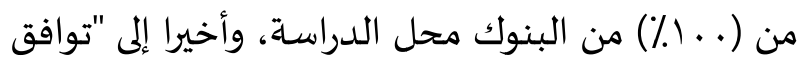
تام" وهي المعايير التي يلتزم بها كل البنوك محل الدراسة.

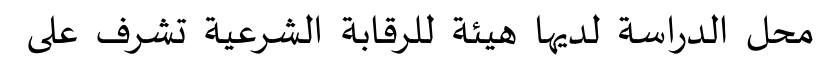

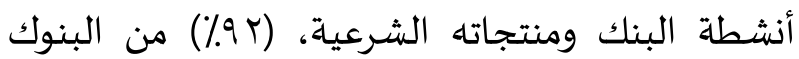
يرفضون التحديد المسبق لنسبة العوض على ودائع

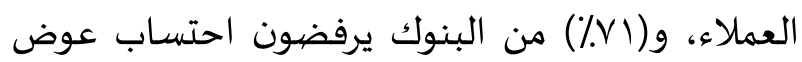

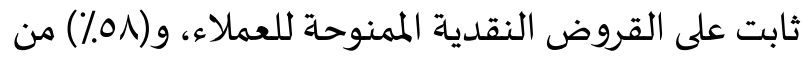
البنوك لا يقومون بمشاركة عميل المشاركة في الخسائر

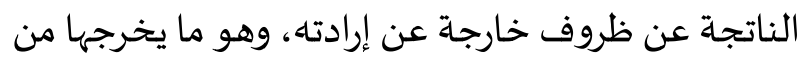
نطاق عمليات المشاركة وفقا لقواعد الاقتصاد الإسلامي. كما وجدت الدراسة أن (IV/) من البنوك محل الدراسة 
جدول رقم (1) نتائج تحليل الاستبيان وقيمة المعيار الفني المقترح

\begin{tabular}{|c|c|c|c|}
\hline معيار التزام البنك بقواعد & بالمعايير الفرعية التزام البنك & بالمعايير الحاكمة التزام البنك & الرمز (Code) \\
\hline . ro & $\%$ & $\%$ & 1 \\
\hline .09 & $\% 0 \Lambda, 7$ & $\%$ & $r$ \\
\hline . & $/ 71, \varepsilon$ & $\%$ & r \\
\hline.,$V \varepsilon$ & $\% / 7,7$ & $\%$. & $\varepsilon$ \\
\hline ., & $\% \vee \backslash, \varepsilon$ & $\% 9$. & 0 \\
\hline ع & $\%$ \% , & \%. & 7 \\
\hline., 95 & $\%$ I.A,$r$ & $\% 1 \ldots$ & V \\
\hline.,$V \varepsilon$ & $\%$ \%М, 7 & $\%$ & $\Lambda$ \\
\hline., 01 & $\% 71, \varepsilon$ & $\%$ \%. & 9 \\
\hline., 07 & $\% 0 r, 9$ & $\%$. & 1. \\
\hline., 71 & $/ 71, \varepsilon$ & $\%$ & 11 \\
\hline., $\mathrm{VA}$ & $\% \mathrm{VO}, \mathrm{V}$ & $\%$. & Ir \\
\hline., $\mathrm{VA}$ & $\%(70, \mathrm{~V}$ & $\% 9$. & $\pi$ \\
\hline., 79 & $\% \vee \wedge, 7$ & $\%$ & $1 \varepsilon$ \\
\hline זT, . & $\% \vee \varepsilon, r$ & $\%$ & 10 \\
\hline., 70 & $\%$ & $\%$ & 17 \\
\hline., 19 & $\% \vee \wedge, 7$ & $\%$ & IV \\
\hline., $\mathrm{V} 9$ & $\% 7 \mathrm{~V}, 1$ & $\%$ & 11 \\
\hline., 90 & $\%$ & $\% \ldots$ & 19 \\
\hline.,$V r$ & $\%(\wedge 0, \mathrm{~V}$ & $\%$ & $r$. \\
\hline.,$\sum 7$ & $\%$.0r, 9 & $\%$ \%. & YI \\
\hline .09 & $\% 01,7$ & $\%$ & Yr \\
\hline T & $\%(\mathcal{L}, \Gamma$ & $\%$. & $r \mu$ \\
\hline .,AY & $\% \vee v \varepsilon, r$ & $\%$ & $r \varepsilon$ \\
\hline
\end{tabular}

المصددر: من إعداد الباحثين بناءً على معطيات الدراسة. 
جدول رقم (Y) درجة توافق البنوك على الالتزام بالمعايير الفرعي

\begin{tabular}{|c|c|c|}
\hline التساؤل الذي يعكس المعيار الشرعي. & رقمبر & 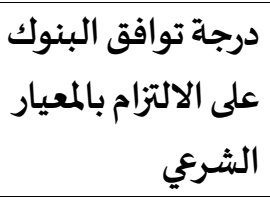 \\
\hline لا يقوم البنك ببيع وشراء العملات الأجنبية بسداد مؤجل. & 1.01 & \multirow{5}{*}{ 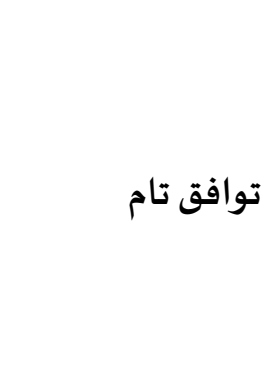 } \\
\hline لا يشترط البنك بتوقيع العميل على عقد كفاله ووكالة في عقدا واحد. & 5.02 & \\
\hline لا يقوم البنك بتجديد المرابحة على نفس السلعة عدة مرات. & 7.02 & \\
\hline 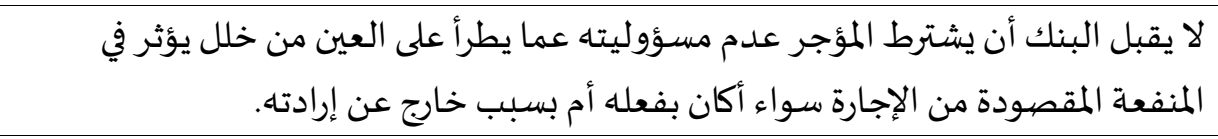 & 9.02 & \\
\hline لا يلتزم البنك أن يقدم هدايا عينية أو مالية أو خدمات لأصحاب الحسابات الجارية . & 19.03 & \\
\hline لا يقبل البنك الوعد ببيع العملة الأجنبية في حاله قيام العميل الوعد بالسداد. & 1.03 & \multirow{21}{*}{ 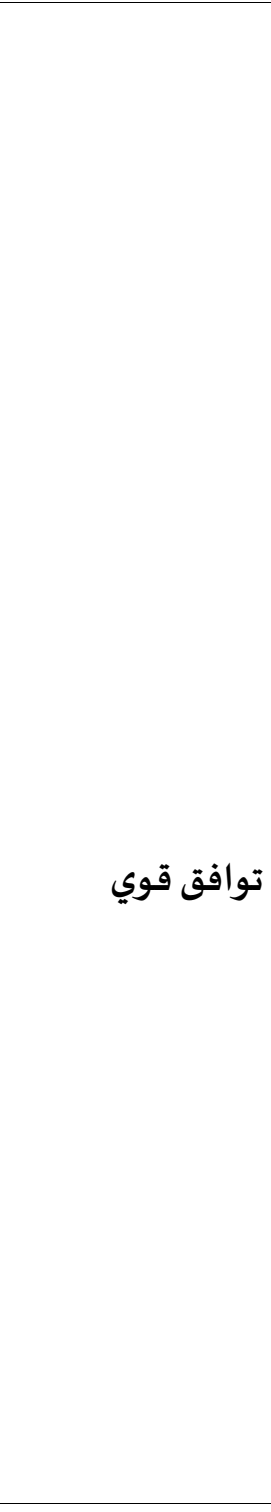 } \\
\hline لا يمكن لعميل البنك أن ينيب البنك للمتاجرة بالعملات بمبالغ اكثر مما يملك . & 1.05 & \\
\hline لا عندما يقرض البنك العميل يشترط عليه المتاجرة بالعملات معاه فقط. & 1.06 & \\
\hline لا يصدر البنك بطاقات ائتمان ذات الدين المتجدد. ل & 2.02 & \\
\hline لا يشترط البنك تعويض مالي اذا تأخر المدين عن سداد المستحق عليه. & 3.01 & \\
\hline لا يقوم البنك بتجميد الحساب الجاري للعميل جبرا كضمان في عمليات المداينة. & 5.06 & \\
\hline لا يقبل البنك خصهم الأوراق التجارية ودفع القيمة المقطوعة عند قيام مالكها بتظهيرها للبنك. & 7.01 & \\
\hline لا يقوم البنك حجز إجمالي مبلغ هامش الجدية في حالة امتناع العميل عن تنفيذ وعده. & 7.06 & \\
\hline لا يستطيع البنك زيادة أجرة العين المؤجرة عن الفترات السـابقة. & 9.04 & \\
\hline لا يقوم البنك بزيادة الأجرة للعين المؤجر في حال التأخر في السـداد. ل & 9.05 & \\
\hline لا يشترط البنك الحصيول على مبلغ مقطوع من الأرباح عند الدخول في الشركات المتناقصية. & 12.15 & \\
\hline لا يقبل البنك أن يقرض أو يتصهدق أو يتنازل المضهارب من مال المضياربة بدون إذن مسبق من البنك. & 13.04 & \\
\hline تحتوى محفظة ضيمانات البنك على سندات واسهم لجميع أنواع الشركات من كل أنحاء العالم. & 14.01 & \\
\hline لا يقوم البنك بخصيم الكمبيالات التي قام باعتمادها من قبل ودفع القيمة المقطوعة عند & 14.02 & \\
\hline لا يمكن للبنك إجراء تداول للمستندات مؤجلة الدفع. ل & 14.03 & \\
\hline لا يقوم البنك بتداول مستندات الاطلاع أو الكمبيالات بأقل من قيمتها. & 14.04 & \\
\hline لا يقوم البنك ببيع الورقة التجارية المخصومة لدية بمثل قيمتها أو أكثر . & 16.03 & \\
\hline لا يقوم البنك بتداول صكوك ملكية منافع الأعيان الموصوفة قبل تعيين العين محل المنفعة. & 17.01 & \\
\hline لا يتداول البنك صكوك ملكية الخدمات قبل تعيين الطرف الذي تستوفى منه الخدمة. & 17.02 & \\
\hline تأجيل السـترط البنك زيادة القرض سواء في الصيفة أو في المقدار أو في المنفعة عند طلب العميل & 19.01 & \\
\hline لا يقوم البنك بالتعامل في عقود المستقبليات (options) والمبادلات المؤقتة (sutures) والاختيارات (swaps). & 20.01 & \\
\hline
\end{tabular}




\begin{tabular}{|c|c|c|}
\hline التسـاؤل الذي يعكس المعيار الشرعي. & رقمث & على الشعة توافق البنوك \\
\hline عمليات المشترط البنك الحصول على أو المضاربة. & 24.01 & \\
\hline لا يقوم البنك بتأجير الأعيان الموقوفة بأي قيمة بدل من تركها بدون إيجار. & 33.01 & \\
\hline لا يقوم البنك بزيادة الإيجار إذا تأخر المستأجر عن السداد. & 34.04 & \\
\hline لا يحصل البنك على عمولة ارتباط على القروض مباشرة أو الحسـابات الجارية المدينة. & 37.03 & \\
\hline لا يحصل البنك على أرباح مقابل مد أجل سداد المديونية المستحقة. & 37.05 & \\
\hline لا يقبل البنك ديون من بنوك غير إسلامية كرهن للعمليات الائتمانية. & 39.02 & \\
\hline تقلبات أسعار العملات الأجنبية. المشاركة أو المضاربة تقديم العميل التزام بالحماية من مخاطر & 1.04 & \multirow{17}{*}{ توافق متوسط } \\
\hline لا يخصم البنك من العميل رسما مقطوعا يتناسب مع المبلغ المسحوب نقدا من بطاقة الائتمان. & 2.03 & \\
\hline لا يشترط البنك أن يقدم المستأجر كفاله أو رهن لاستيفاء حق البنك عند هلاك العين المؤجرة. & 5.03 & \\
\hline لا يقوم البنك بتحصيل عمولات الارتباط من العملاء. ل & 7.04 & \\
\hline لا يقوم العميل بدفع عموله تسهيلات ائتمانية ليتمكن من الحصول على التسهيلات المطلوبة. & 7.05 & \\
\hline لا يقوم البنك باستلام سلع المرابحة من البائع وتخزينها فعليا قبل أن يقوم ببيعها للمشترى. & 8.01 & \\
\hline لا يعتبر البنك عقد المرابحة للآمر بالشراء مبرما تلقائيا بمجرد تملك البنك السلعة. & 8.02 & \\
\hline لا يقوم البنك بإلزام عميل الآمر بالشراء بتسلم السلعة وسـاد ثمن بيع المرابحة في حالة & 8.03 & \\
\hline لا يمكن للعميل تأجيل سداد الدين مقابل زياده في مقداره. & 8.04 & \\
\hline لا يقبل البنك رهن صكوك السلم القابلة للتداول. & 10.08 & \\
\hline لا يشترط البنك تخفيض الثمن عند تعجيل السداد عقود السلم. & 11.07 & \\
\hline لا يقوم البنك بإقراض المساهم لشراء الأسهم في الشركات المساهمة بشرط رهن الأسهم للبنك. & 12.09 & \\
\hline لا يقبل البنك التعامل في الأسهم الممتازة التي لها الأولوية عند التصفية للشركات المساهمة. & 12.11 & \\
\hline لالدول يقوم البنك بدفع فوائد نتيجة العمليات المصرفية مع المؤسسـات والبنوك والمراسلين في & 14.06 & \\
\hline لا يقوم للبنك بحسم (خصهم) الأوراق التجارية ويدفح أقل من قيمتها قبل حلول أجلها لغير & 16.02 & \\
\hline لا يقوم البنك بتداول صكوك المرابحة بعد تسليم البضاعة للمشتري. ل & 17.04 & \\
\hline لا يقوم البنك بتداول صيكوك المزارعة والمساقاة اذا كان حملة الصكوك من الملتزمين بالعمل & 17.05 & \\
\hline
\end{tabular}




\begin{tabular}{|c|c|c|}
\hline التسـاؤل الذي يعكس المعيار الشرعي. & المعيار & على الالتزام بالمعيار البنوك \\
\hline لا لا يشترط البنك أن يكفل مدير المضاربة أو المشاركة المدينين وتقلبات أسعار صرف العملة & 24.02 & \\
\hline لا لا يشترط البنك أن يقدم مدير المضاربة أو المشاركة تعهد بحماية عملية المشـاركة أو & 24.03 & \\
\hline لا يقوم البنك بربط مقدار الدين النقدي بحركة مؤشرات الأسعار. & 27.05 & \\
\hline لا يوجد لدى البنك صندوق للزكاة. ل & 35.01 & \\
\hline لا يحصل البنان والاعتمادات على عوائد تفوق التستندية. & 37.04 & \\
\hline لا لا يقوم البنك باحتسـاب غرامات تأخير في حاله عدم سداد حامل البطاقة الائتمانية المبلغ & 2.01 & \multirow{16}{*}{ توافق ضعيف } \\
\hline لا يشترط البنك وجود كفيل أو رهن مادى في عقود الأمانة. & 5.01 & \\
\hline لا يقوم العميل بدفع رسوم مقابل الكفالة. ل & 5.04 & \\
\hline لا يقوم العميل بدفع رسوم مقابل إصدار خطاب الضمان نظير قيام البنك بضمانته. & 5.05 & \\
\hline لا يحدد البنك الأغراض التي يتم تأجير عقارته المملوكة له أيا كانت. & 9.01 & \\
\hline لا يشترط البنك في عقد الإجارة أن يقوم المستأجر بأجراء الصيانة الأساسية للعين المؤجرة & 9.03 & \\
\hline لا يقوم البنك بالمرابحة في الاستصناع بتحديد زيادة معلومة عن التكلفة الفعلية. & 11.06 & \\
\hline لا يقبل البنك الربط بين عقد الاستصناع وعقد الاستصناع الموازي. & 11.09 & \\
\hline لا يشترط البنك على المضارب أن يأخذ موافقتاه في كل أمور المضاربة. . & 13.03 & \\
\hline لاليقيقوم البنك بالتعامل بالكمبيالات والسندات لأمر فيما يشترط فياه القبض، مثل جعلهما & 16.01 & \\
\hline لا يمكن للطرفين تعديل إيجار الفترات السابقة والمستقبلية للأعيان المؤجرة. & 34.03 & \\
\hline لا يقوم البنك بإخراج الزكاة عن أرباحه . & 35.02 & \\
\hline لا يمكن للبنك التعامل بالضمانات والاعتمادات غير المغطاة الصيادرة من البنوك التقليدية. & 37.01 & \\
\hline لا يحصل البنك على عمولة مقابل منح أو تجديد أو تمديد التسهيلات الائتمانية. & 37.02 & \\
\hline لا يشترط البنك وجود رهن في حالات عقود الأمانة والوكالة والإيداع والمشاركة والمضياربة. & 39.03 & \\
\hline يقبل البنك أن تمثل الأسهم الممتازة وأسهم التمتع والسندات وشهادات الاستثمار والإيداع & 39.04 & \\
\hline
\end{tabular}




\section{V- خلاصية الدراسـة والتوصيات}

أسباب انصراف البنوك عن بعض المعايير وكيفية تلافي صعوباتها وكيفية تشجيعهم على الالتزام بها.

من أهم الصعوبات التي أثرت في نتائج الدراسـة صغر حجم العينة نتيجة إحجام بعض البنوك عن ملئ الاستبيان بالإضافة إلى أن الإضطرابات السياسية والعسكرية في بعض دول المنطقة كان لها أثر سلبي على الإنيان الإنيان الإستجابا للإستبيانات. يقترح فريق البحث إضافة بنوك

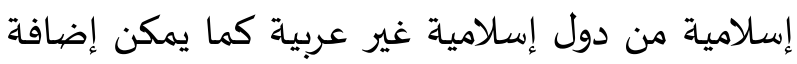
بنوك إسلامية من دول غير إسلامياة، وهذا يؤدى إلى زياده حجم العينة ويثرى البحث. كما يقترح فريق البحث تحديد بنك معياري (Benchmark) يتم في ضيوئه المقارنة مع

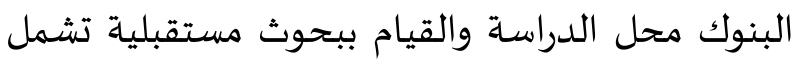
معايير محاسبية، ومعايير المسؤولية الاجتماعياة، ودرجهاء المخاطر بالإضافة للمعايير الشرعية بما يضمن دقة الحكم على شرعية وكفاءة البنك مما قد يساعد في بناء معيار شامل ومتكامل للحكم على هوية المعاملات التي يمارسها البنك وصبغتها بالصبغة الإسلامية وتوافقها مع الاقتصياد

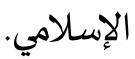

هدفت الدراسـة إلى بناء معيار فني متخصص لقياس مدى اتباع البنوك الإسلامية للمعايير الشرعية في عملياتها

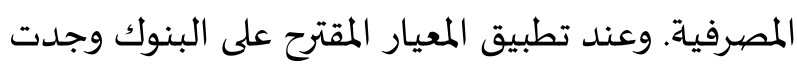

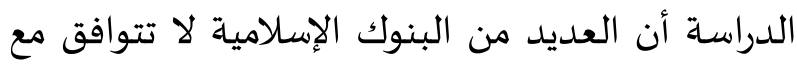

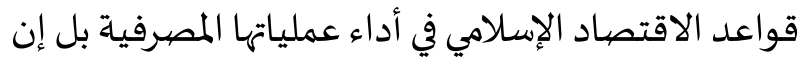
بعض المعاملات تكاد تخرجها من هويتها الإسلامية فقد تراوحت ذسب التزامها بالمعايير الحاكمة ما بين (.ب/\%) و( . (1))، ونسبة التزامها بالمعايير الفرعية ما بين (وץ/\%)

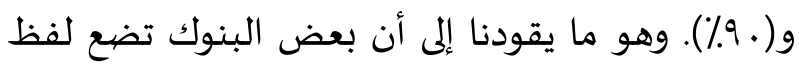
إسلامي لإستقطاب العملاء ذوى التوجهات الإسلامية بدون العمل على تبنى الهوية الإسلامية. وعليه توصي الدراسة بإجراء اختبار معيار الشرعية على كل البنوك

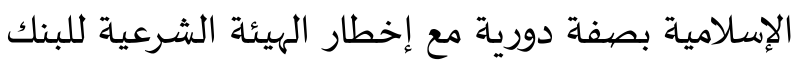

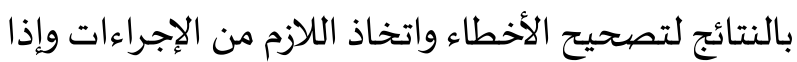
لم يقم البنك بتصحيح المخالفات يتم نشر النتائج مما

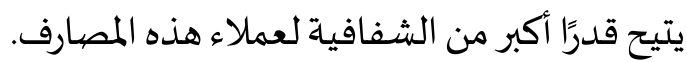
كما لوحظ أيضًا إقبال البنوك على الالتزام ببعض

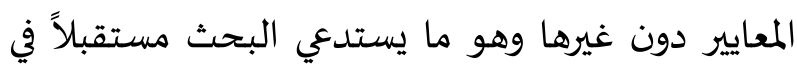




$$
\begin{aligned}
& \text { عمر، محمد عبدالحليم (0.rام) معايير تقويم الأداء في } \\
& \text { المصارف الإسلامية، جامعة الجزائر، كلية الدراسات }
\end{aligned}
$$

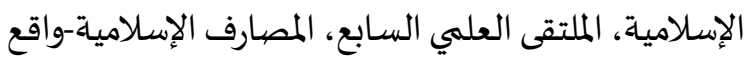

$$
\begin{aligned}
& \text { وآفاق. } \\
& \text { غيث، مجدي علي محمد (10 • rم) "اثثر الدوافح العقدية } \\
& \text { والأخلاقية في تحقيق الرفاهية الاجتماعية والاقتصادية في } \\
& \text { الاقتصاد الإسلامي"، المجلة الأردنية في الاجلية الدراسات }
\end{aligned}
$$

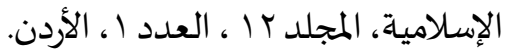

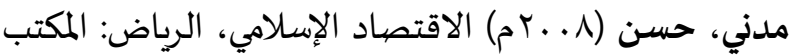

$$
\begin{aligned}
& \text { التعاوني للدعوة، المملكة العربية السعودية. }
\end{aligned}
$$

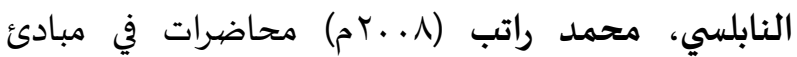

$$
\begin{aligned}
& \text { الاقتصاد الإسلامي. متوفر على الموقع التالي: }
\end{aligned}
$$

http://www.nabulsi.com/blue/ar/art.php?art=5941\&id=175 \&sid=179\&ssid=180\&sssid=181

$$
\begin{aligned}
& \text { النجار، أحمد (.91 1م) البنوك الإسلامية وأثرها في تطوير }
\end{aligned}
$$

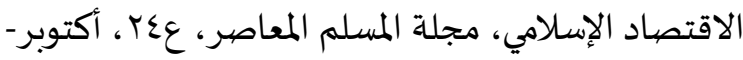

$$
\begin{aligned}
& \text { نوفمبر • 191 ، صعال 1 ، جمهورية مصر العربية. }
\end{aligned}
$$

Alamer, A.R.A., Salamon, H.B., Qureshi, M.I. and Rasli, A.M. (2015) A New Business Process and Outcome Oriented Corporate Social Responsibility Index for Islamic Banking. International Journal of Economics and Financial Issues, 5, 207-214

Asutay, M. and Harningtyas, A.F. (2015) Developing Maqasid al-Shari'ah Index to Evaluate Social Performance of Islamic Banks: A Conceptual and Empirical Attempt. Uluslararası Íslam Ekonomisi ve Finansı Araştırmaları Dergisi, 1(1).

Daly, S. and Frikha, M. (2015) Determinants of bank Performance: Comparative Study between Conventional and Islamic Banking in Bahrain. Journal of the Knowledge Economy, 1-18.

Ebrahim, P.M. and Tarazi, A. Islamic Banking and Finance: Recent Empirical Literature and Directions for Future Research.

El-Masry and Alharthi (2014) Efficiency and its Determinants in Banks: a comparative study of Islamic, Conventional and Socially Responsible Banks.

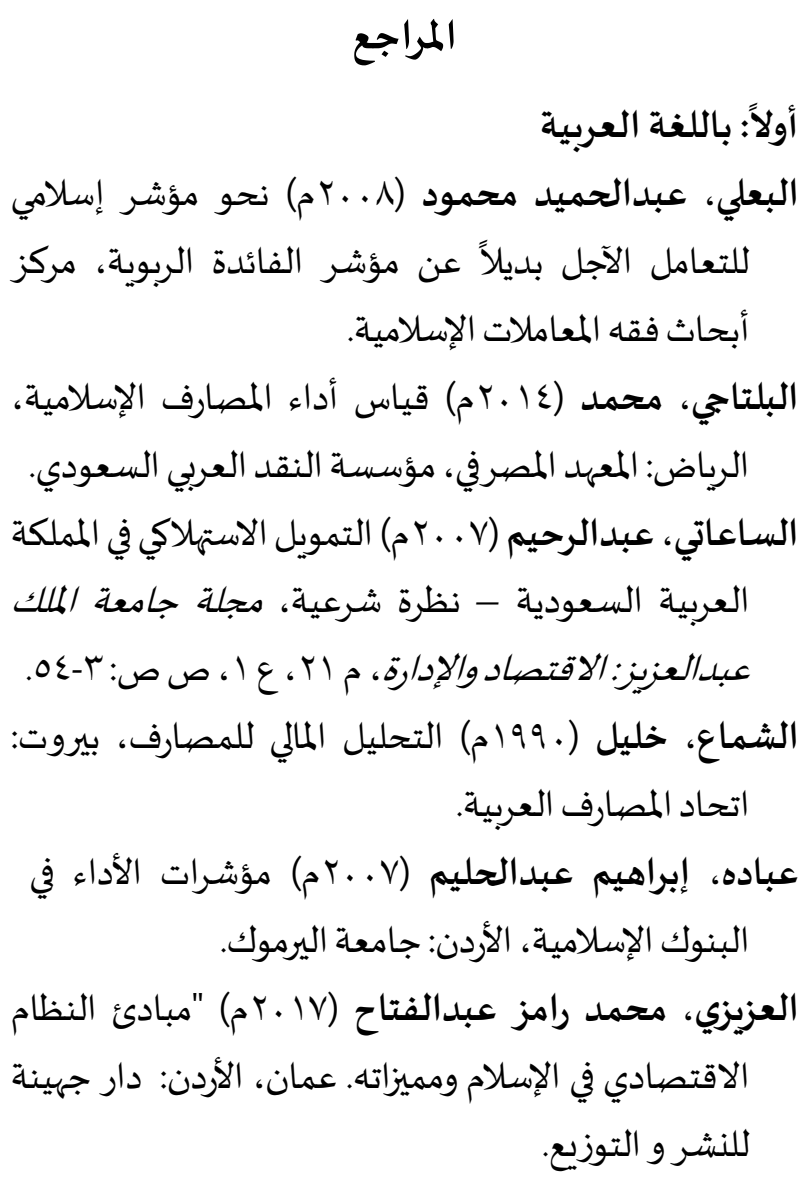

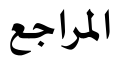

Hadriche, M. (2015) Banks Performance Determinants: Comparative Analysis between Conventional and Islamic Banks from GCC Countries. International Journal of Economics and Finance, 7(9), p169.

Hsu, Chia-Chien and Brian A. Sandford. (2007) "The Delphi technique: making sense of consensus." Practical assessment, research \& evaluation 12 , no. 10: 1-8.

Ibrahim, M. (2015) A Comparative Study of Financial Performance between Conventional and Islamic Banking in United Arab Emirates. International Journal of Economics and Financial Issues, 5(4), 868-874.

Ibrahim, M. (2015) Measuring the Financial Performance of Islamic Banks. Journal of Applied Finance and Banking, 5(3), 93.

Loke, J.C., Ong, E.P., Lim, S.S. and Yeoh, S.C. (2015). Factors affecting performance of Islamic banks and conventional banks: Evidence from Malaysia (Doctoral dissertation, UTAR). 
Mohammad, M.O. and Shahwan, S. (2013) The objective of Islamic economic and Islamic banking in light of Maqasid Al-Shariah: A critical review. MiddleEast Journal of Scientific Research, 13, 75-84.

Mohammed, M.O. and Taib, F.M. (2015) Developing Islamic banking performance measures based on maqasid al-shari'ah framework: cases of 24 selected banks. Journal of Islamic Monetary Economics and Finance, 1(1), 55-77

Moin, M.S. (2008) Performance of Islamic banking and conventional banking in Pakistan: a comparative study. Full source

Rahim, S.R.M. (2015) How Efficient Are Islamic Banks in Malaysia?. Journal of Business Studies Quarterly, 6(3), 164?.

\section{Translation of Arabic References}

Al-Najjar, Ahmad (1980) Islamic Banks and their Impact on the Development of the Islamic Economy, Journal of Modern Muslim, p. 24, October-November 1980, p. 164.

Al-Sahati, Abdul Rahim (2007) Consumer Finance in the Kingdom of Saudi Arabia - A Legitimate Perspective, Journal of King Abdulaziz University: Economics and Management, 21-21 p.

Al-Shamma, Khalil (1990) Financial Analysis of Banks, Union of Arab Banks, Beirut, p. 14

Azizi, Muhammad Ramez Abdul Fattah (2017) "Principles of the economic system in Islam and its advantages".

Baali, Abdul Hamid Mahmoud (2008) towards an Islamic index of the future deal in lieu of interest rate interest, the Center for Research on the jurisprudence of Islamic transactions.
Saleh, A.S. and Zeitun, R. (2006) Islamic banking performance in the Middle East: A case study of Jordan. Faculty of Commerce-Economics Working Papers, 157.

Srairi, S., Kouki, I. and Harrathi, N. (2015) The relationship between Islamic bank efficiency and stock market performance: Evidence from GCC countries. Islamic banking and finance-Essays on corporate finance, efficiency and product development, 125.

World Islamic Banking Competitiveness Report 2016 http://www.ey.com/Publication/vwLUAssets/eyworld-islamic-banking-competitiveness-report2016/\$FILE/ey-world-islamic-bankingcompetitiveness-report-2016.pdf

Ebada, Ibrahim Abdel Halim (2007) Performance Indicators in Islamic Banks, Yarmouk University, Jordan.

El-Beltagy, Mohamed (2014) Measuring the performance of Islamic banks, Institute of Banking Saudi Arabian Monetary Agency.

ELNabulsi, Mohammad Rateb (2008) Lectures in the principles of Islamic economics, 2008-12-02

Ghaith, Magdy Ali Mohamed (2015) "The Impact of Stochastic and Ethical Motives on Achieving Social and Economic Welfare in the Islamic Economy."

Madani, Hassan (2008) Islamic Economics, Cooperative Office for Propagation, Riyadh.

Omar, Mohamed Abdel Halim (2005) Performance Standards in Islamic Banks, University of Algeria, College of Islamic Studies, Seventh Scientific Forum, Islamic Banks - Reality and Horizons. 


\title{
The Extent to which Islamic Banking Transactions Are Compatible with the Rules of Islamic Economics
}

\author{
Osama Mohamed Badr*, Ahmed Ahmed El-Masry ${ }^{* *}$ \\ and Khaled Ibrahim Sayed Ahmed ${ }^{* * *}$ \\ *Associate Professor, Faculty of Administration, Umm Al-Qura University, Saudi Arabia \\ ${ }^{* *}$ Associate Professor, Plymouth University (UK); Mansoura University (Egypt); \\ Umm Al-Qura, University, Saudi Arabia \\ *** Assistant Professor, Faculty of Commerce, Tanta University, Egypt
}

\begin{abstract}
According to existing literature in Islamic economics the implantation of the idea of Islamic banks emerged in the Egyptian countryside in 1963. Thereafter, this kind of institutions have spread all over the world to reach more than 700 banks operating in 60 countries with 38 million customers around the world with total assets of up to $\$ 2$ trillion according to latest reports. However, the practices of these institutions have given rise to a very critical question: Are the existing Islamic banks practicing their transactions according to Islamic Shari'ah in substance rather than the forum? The objective of this study is to develop a specialized technical criterion to assess the extent to which Islamic banks adhere to the rules of the Islamic economics. Thus, the technical criterion was designed and then applied to a sample of Islamic banks in the Arab world. The study found that the percentage of banks that comply with the rules of the Islamic economics ranges between $29 \%$ and $90 \%$ of the Shari'ah standards. Therefore, the study recommends applying this test of Shari'ah standards on a regular basis to all Islamic banks to notify the Shari'ah boards of these banks with the results of the test, thus, paving the way for greater transparency of the customers of these banks.
\end{abstract}

Keywords: Islamic Economy, Islamic Banks, Sharia Banking Standards, Islamic Banking Transactions, evaluating the performance of Islamic banks, AAOIFI Standards.

JEL Classification: E4

KAUJIE Classification: B04, Q23, I0 , L11, L21 
حصل أسامة محممد بدر على بكالوريوس التجارة عام 9177 م، وعلى شهادة المحلل المالي للأسهم

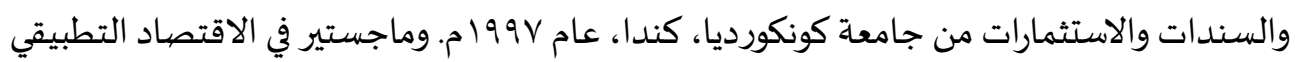

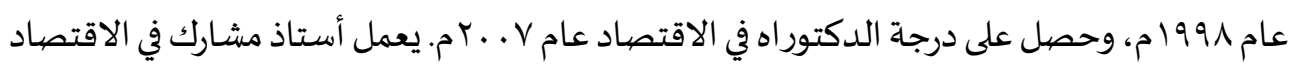

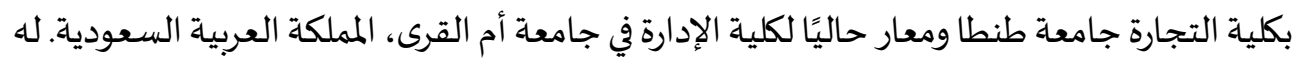

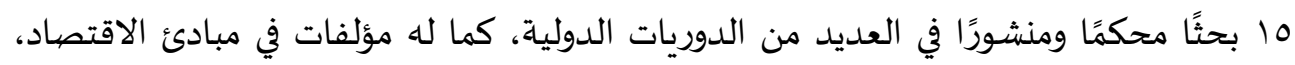

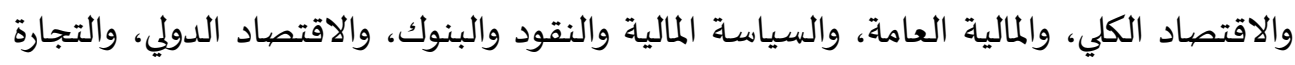

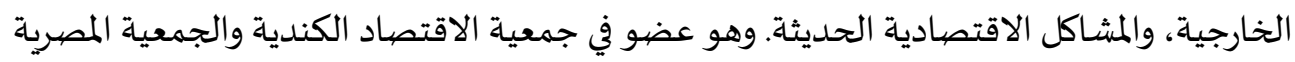
للاقتصاد والتشريع والإحصياء. البريد الإلكتروني: osbadr@yahoo.com.

حصل أحمد أحمد المصري على دكتوراه في التمويل من جامعة مانشيستر بالمملكاة المتحدة، يعمل

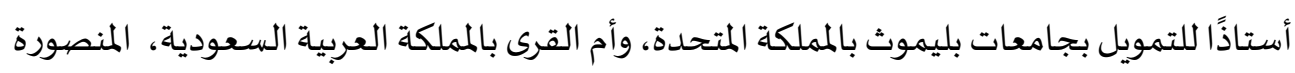

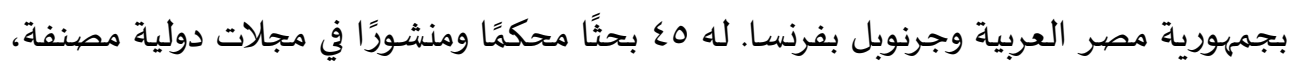

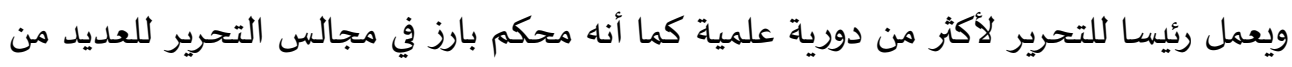

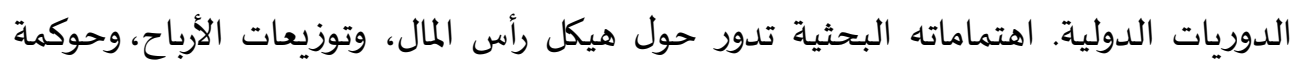

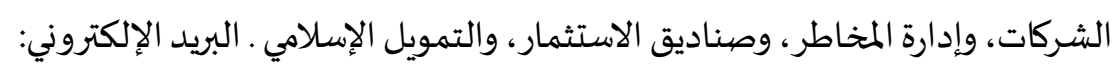
.ahmed.el-masry@plymouth.ac.uk

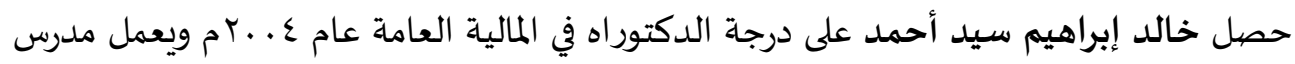
بقسم الاقتصاد والمالية العامة بكلية التجارة جامعاة طنطا، أعير للعمل بكلية الاقتصاد وإدارة الأعمال

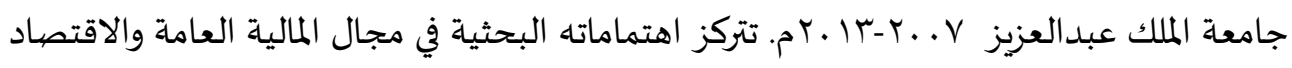

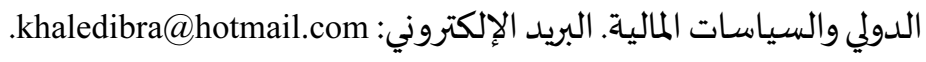

